\title{
GESTÃO DA VIDA E BIOPOLÍTICA NAS TRAMAS E TECITURAS DA COVID-19 NO BRASIL ${ }^{1}$
}

\author{
LIFE MANAGEMENT AND BIOPOLITICS IN THE WEFT AND WOOF OF \\ COVID-19 IN BRAZIL
}

Kleiton Wagner Alves da Silva Nogueira *

\begin{abstract}
Resumo
Isolamento social, fechamento de fronteiras, quarentena e vigilância populacional por meio de dispositivos tecnológicos foram algumas das medidas tomadas pelos diferentes governos com o advento da pandemia de Covid-19. Tendo por base essa consideração, o presente artigo apresenta como objetivo refletir acerca da pandemia de Covid-19 por meio da leitura do conceito de biopolítica expresso pelo autor francês Michel Foucault. Por meio da revisão bibliográfica e análise documental, buscamos verificar empiricamente a aproximação do referido conceito para pensar a atuação governamental no Brasil mediante decretos do Governo Federal referentes à pandemia. Como resultados, foi possível observar uma série de dispositivos vinculados ao controle e vigilância dos corpos institucionalizados por um saber-poder médico que se liga ao controle socioespacial e biológico da vida. Além disso, chamou atenção a forma como a biopolítica tem sido praticada: evidências empíricas demonstram que o deixar morrer tem sido um dos enfoques de Bolsonaro na gestão da crise sanitária com o objetivo de priorizar um retorno imediato das atividades econômicas.
\end{abstract}

Palavras-chave: Biopolítica; Governo Bolsonaro; Covid-19; Pandemia.

\begin{abstract}
Social isolation, border closure, quarantine and population surveillance through technological devices were some of the measures taken by different governments with the advent of the Covid19 pandemic. Based on this consideration, the present article reflects on the covid-19 pandemic through a reading the concept of biopolitics in the work of Michel Foucault. Through bibliographic review and document analysis, we seek to empirically verify the approximation of the referred concept in order to reflect on governmental action in Brazil, through federal government decrees regarding the pandemic. As a result, it was possible to observe a series of devices linked to the control and surveillance of bodies institutionalized by medical knowledge and power, which are linked to socio-spatial and biological control over life. Beyond this attention has been drawn to the way biopolitics has been practiced. Empirical evidence has shown that letting die has been one of Bolsonaro's approaches in managing the health crisis with the aim of prioritizing an immediate return to economic activities.
\end{abstract}

Keywords: Biopolitics; Bolsonaro Government; Covid-19; Pandemic.

\footnotetext{
${ }^{1} \mathrm{O}$ presente trabalho foi realizado com apoio da Coordenação de Aperfeiçoamento de Pessoal de Nível Superior - Brasil (CAPES), e elaborado a partir das discussões e leituras de textos realizadas na disciplina Seminários Avançados II, ministrada pela professora Dra. Mércia Rejane Rangel Batista e pelo professor Dr. José Gabriel Silveira Corrêa no período 2020.2 no Programa de Pós-Graduação em Ciências Sociais da Universidade Federal de Campina Grande.

* Doutorando no Programa de Pós-Graduação em Ciências Sociais da Universidade Federal de Campina Grande/Brasil. E-mail: kleiton_wagner@hotmail.com.
} 


\section{Introdução}

Era comum nos indagarmos quando alguém no ônibus, centro da cidade, parque etc. utilizava uma máscara cirúrgica como utensílio de proteção à saúde. Em nossa imaginação, tais pessoas apresentavam uma saúde fragilizada, detentoras de alguma patologia mortal. Com a pandemia do Corona Virus Disease (Covid-19), todas essas imagens foram experienciadas em nosso cotidiano. A patologia causada pelo novo coronavírus (Sars-Cov-2) surgiu no final do ano de 2019, com o registro de casos de pneumonia viral em Wuhan, na China. Seus sintomas mais comuns são: febre; tosse seca e fadiga corporal. Contudo esses sintomas podem evoluir para: diarreia, perda de paladar, congestão nasal, dores musculares, articulares, na cabeça e na garganta. Nos casos mais graves, o quadro infeccioso apresenta: falta de ar, perda de apetite, temperatura corporal acima de $38^{\circ} \mathrm{C}$ e dor persistente ou pressão no peito (WHO, 2020). A rápida forma de contágio, por meio de gotículas e aerossóis contendo o Sars-Cov-2, além da conexão mundial mediante voos internacionais, relações comerciais e turismo, logo fizeram com que a doença se espalhasse pelo mundo, causando inúmeras mortes e se tornando um dos problemas centrais para os distintos governos no mundo.

Embora a humanidade conviva com patologias desde os tempos mais remotos, basta um passeio na literatura de Defoe ([1722]); Camus ([1947] 2012) e Galeano ([1971] 2010) para observarmos o tema das pandemias e epidemias como partes inerentes ao desenvolvimento das sociedades humanas. A relação entre homem, natureza, desenvolvimento de meios e modos de produção ao longo da história tem provado que tal fenômeno não é exclusivo de nossa época. Não obstante, é preciso que reconheçamos que o desenvolvimento da técnica, da ciência e da informação desde o pós-Segunda Guerra Mundial têm potencializado uma maior disseminação em escala planetária.

Nesse sentido, pensar a relação entre sociedade e pandemia, dentro do âmbito das Ciências Sociais, é um esforço válido, tendo em consideração que essa área trabalha com autores e conceitos de diferentes campos do saber, como é o caso da produção intelectual do filósofo francês Michael Foucault (1926-1984), autor que possui uma vasta obra, mas que por meio de seus estudos sobre a loucura, sexualidade e encarceramento, forneceu subsídios para que os cientistas sociais pudessem promover análises acerca do tema da saúde, especialmente pelo conceito de biopolítica. Dessa forma, a pandemia de Covid-19, 
certamente surge como um fenômeno de ordem global, mas que também expressa formas de controle por meio da ação governamental sobre a saúde e a morte das pessoas, numa relação de poder que expressa a composição de normas e leis aglutinadas em dispositivos jurídicos, e que implicam na forma como devemos nos comportar e viver na pandemia frente às exigências "legais" do Estado.

Dessa forma, ao recuperar essa linha de raciocínio, o presente artigo tem por objetivo realizar uma reflexão acerca da pandemia de Covid-19 por meio da leitura do conceito de biopolítica de Foucault. Para o alcance desse objetivo, realizamos o levantamento da bibliografia das obras do autor, além de uma análise documental sobre os principais decretos emitidos pelo Governo Federal e que tratam do aspecto da saúde e enfrentamento à Covid-19.

Do ponto de vista de nossa exposição, realizamos inicialmente um panorama sobre a gestão e o poder como elementos que atuam sobre a vida tendo em mente as considerações de Foucault. Na segunda parte, há um itinerário reflexivo que busca associar biopolítica com o processo de governar, com ênfase na saúde como um dos elementos fundantes dessa concepção. Em seguida, realizamos um balanço empírico com base na crise sanitária brasileira, no qual se utilizou dispositivos jurídicos emanados pelo Governo Federal de modo a associarmos empiria e apontamentos teóricos sobre a biopolítica.

\section{Gestão e poder sobre a vida}

Vida e morte, elementos dialéticos e constituintes da existência humana, não podem ser considerados de modo homogêneo e linear, tendo em vista que as determinações sociais em cada formação econômico-social condicionam o modo como os seres humanos experienciam formas de viver e de morrer. Todavia, morrer e viver também implicam numa concepção de gestão, na maneira como as forças produtivas foram se desenvolvendo a partir das relações sociais de produção. Essa correlação traduziu a condição humana de se preocupar com tais instâncias por intermédio da criação de dispositivos e instituições que regulam a forma como nascemos, vivemos e morremos em sociedade. 
Nesse sentido, Michael Foucault, mesmo que não tenha se detido exclusivamente à área da saúde, promoveu em seu exercício teórico, marcado por uma genealogia e arqueologia do saber, a ideia de que a morte, assim como a vida, está intimamente associada com relações de poder. Segundo a filósofa e pesquisadora italiana Laura Bazzicalupo (2017), essa concepção de Foucault pode ser apreendida no que o filósofo francês denominou como biopolítica. Para a pesquisadora, o termo está cada vez mais presente no cotidiano, e surge em contextos diferenciados, vinculados aos problemas da vida. E é a partir de Foucault que a noção ganha uma modelagem e contorno que deduz a forma de se governar vidas no âmbito econômico, social e político.

O uso dos corpos, alimentação, epidemiologia, saúde etc. constituem elementos associados à vida biológica e aos seres viventes, que são foco de ação de um poder sobre a vida na forma de dispositivos jurídicos, elaborados e externalizados por normas e condutas sociais estabelecidas. A vida como objeto passa a ser fonte de análise, observação e atenção do Estado moderno. Se com o absolutismo havia o poder de fazer morrer e deixar viver, com o desenvolvimento do capitalismo e a necessidade de uma gestão dos corpos para a geração de mais-valia, temos uma espécie de inversão na qual a gestão da vida ganha uma tônica que remete ao fazer viver e deixar morrer aqueles corpos necessários e focos de exploração.

Nesse ínterim, cabe salientar que o termo biopolítica, tal como o conhecemos pelas elaborações de Foucault, deriva do século XIX, conforme Laura Bazzicalupo (2017). A observação sobre uma normatização e disciplinamento da vida já era conhecida, antes das elaborações de Foucault, sob uma chave positivada, funcionalista e mecanicista da sociedade, elementos que terão a crítica do autor no decorrer de sua elaboração teóricoempírica. E é justamente sobre esse eixo norteador, positivado e entendido de modo acrítico, que o filósofo vai direcionar suas análises a condição de um poder objetivado no controle da vida pela via dos dispositivos normalizadores e disciplinares da vida. $\mathrm{O}$ surgimento de campos do saber, de verdades e discursos vão se instaurar como elementos pretensos a um regime científico e tecnológico que tem na ciência o baluarte e ancoradouro de sua efetividade, e que estão vinculados à materialidade da vida (BAZZICALUPO, 2017). 
Observamos que a reflexão em torno de como a vida deve ser regida e controlada é fundamental para o entendimento da concepção de biopolítica em Foucault. Considerar essa noção nos ajuda a pensarmos sobre o fenômeno da pandemia de Covid-19, dos modos de governar e da gestão sanitária que têm sido realizada no Brasil.

\section{A biopolítica e o processo de governar}

Uma primeira menção de Foucault ao termo biopolítica, segundo o professor Peter Pelbart (2003), ocorreu em 1974 numa palestra realizada na cidade do Rio de Janeiro, e que tinha como tema o nascimento da medicina social. Nessa palestra, é possível observar a preocupação do filósofo francês em investigar os dispositivos sanitários que controlam a vida das populações por meio de um saber-fazer médico. Foucault ([1963] 2011) vai refletir sobre o fato da técnica, em especial o controle estatístico no âmbito da saúde por intermédio de uma epidemiologia sanitária, passar a contabilizar os elementos da vida, tais como taxas de natalidade, mortalidade etc.

Esses elementos passam a ser detalhados como uma forma de controle político no qual são registrados, além das mortes e óbitos, condições de vida, caracterizações territoriais, alimentação etc. Nesse processo, é esboçado um inventário sobre os elementos associados à forma de viver, e toda essa contabilidade implicou em um saber médico que foi se instaurando como prática normativa sobre o controle da vida e dos corpos: "Na gestão da existência humana, toma uma postura normativa que não a autoriza apenas a distribuir conselhos de vida equilibrada, mas a reger as relações físicas e morais do indivíduo e da sociedade em que vive" (FOUCAULT, [1963] 2011, p. 37).

A concepção em torno do disciplinamento do corpo é parte constitutiva do que teremos na passagem de regimes pautados no absolutismo, que ditavam as formas de morrer, promoviam confiscos e conquistas de territórios, ao deslocamento sobre um poder que fizesse a gestão da vida e necessidade de conformação dos estados modernos. Esse poder sobre a vida se desenvolve a partir do século XVII pela composição de dois elementos específicos: disciplina e uma política da vida da população. A sujeição do corpo ao disciplinamento e ao controle da população, que passa a crescer com o desenvolvimento das forças produtivas, implicaria, na visão do filósofo francês, em elementos constitutivos do biopoder. 
O elemento populacional também chama atenção de Foucault na medida em que exige formas de governar, que pudessem funcionar como gestão do conjunto da vida das pessoas. A questão do governo é tema de reflexão por Foucault ([1963] 2011) de modo a apontar que a partir do século XVI, a questão do governo aparece sobre diferentes aspectos: o governo de si mesmo e dos outros, e o governo das almas regidas pelo cristianismo, no governo das crianças por meio da pedagogia e pelo pastorado. Esse disciplinamento e controle foram essenciais ao desenvolvimento do capitalismo, mas não apenas isso, tendo em vista que havia também a necessidade da elaboração de metodologias que promovessem uma gestão da vida de forma consensual:

[.... o capitalismo exigiu mais do que isso, foi-lhe necessário o crescimento tanto de seu reforço quanto de sua utilizabilidade e sua docilidade; foram-lhe necessários métodos de poder capazes de majorar as forças, as aptidões, a vida em geral, sem por isto torná-las mais difíceis de sujeitar; se o desenvolvimento dos grandes aparelhos de Estado como instituições de poder, garantiu a manutenção das relações de produção [...] (FOUCAULT, 1988, p. 133, grifo nosso).

As instituições a que Foucault faz referência seriam: família, exército, escola, polícia e a medicina de escopo individual e coletiva. É dessa forma que as nuances do capital, a acumulação, mais-valor e expansão das forças produtivas tiveram como parte inerente o exercício do biopoder. Por consequência, esse poder sobre a vida, como argumenta Foucault (1988), teve como função medir, qualificar, avaliar e hierarquizar. Passa-se, assim, de uma sociedade que tinha no poder do soberano o imperativo da morte para uma normatização de regras e criação de ambientes propícios à acumulação de capital e geração de lucro.

Por volta dos anos 1978 e 1979, Foucault proferiu um curso intitulado: O nascimento da biopolítica (FOUCAULT, [1979] 2008). Nesse curso, ele aborda o governo não de forma estrita, mas pontua a melhor forma de governar, a prática de governar. Nesse ínterim, vai considerar que governar, segundo a razão de um Estado, é se tornar sólido; permanente; rico e forte diante das ameaças que o podem destruir. Ao visualizar o Estado como um regime de múltiplas governabilidades, o autor se distancia de uma posição estática e estritamente institucional que enxerga o Estado como um fato imóvel (FOUCAULT, 2002). 
Dessa forma, governamentalidade é entendida como o conjunto de instituições, procedimentos e ações que tem por alvo a população, mas que também implica na conformação do governo por meio de instituições e na atuação de um Estadoadministrativo governamentalizado:

\begin{abstract}
Por esta palavra, 'governamentalidade', entendo o conjunto constituído pelas instituições, os procedimentos, análises e reflexões, os cálculos e as táticas que permitem exercer essa forma bem específica, embora muito complexa, de poder que tem por alvo principal a população, por principal forma de saber a economia política e por instrumento técnico essencial dos dispositivos de segurança. Em segundo lugar, por 'governamentalidade' entendo a tendência, a linha de força que, em todo o Ocidente, não parou de conduzir, e desde há muito, para a preeminência desse tipo de poder que podemos chamar de 'governo' sobre todos os outros - soberania, disciplina - e que trouxe, por um lado, o desenvolvimento de toda uma série de aparelhos específicos de governo [e, por outro lado], o desenvolvimento de toda uma série de saberes. Enfim, por 'governamentalidade', creio que se deveria entender o processo, ou antes, o resultado do processo pelo qual o Estado de justiça da Idade Média, que nos séculos XV e XVI se tornou o Estado administrativo, viu-se pouco a pouco 'governamentalizado' (FOUCAULT, [1978] 2008, p.143-143, grifos do autor).
\end{abstract}

Segundo Oliveira (2019), a governamentalidade seria elaborada por Foucault para explicitar a forma de surgimento do Estado moderno. Para essa autora, esse processo também implicou no tipo de regime de poder e nas especificidades tecnológicas que, após o século XVIII, teve como epicentro a gestão populacional pela biopolítica. Dentro da perspectiva da governamentalidade, a biopolítica é conceituada por Foucault da seguinte forma:

\begin{abstract}
Maneira como se procurou no século XVIII, racionalizar os problemas postos à prática governamental pelos fenômenos próprios de um conjunto de viventes constituídos em população: saúde, higiene, natalidade, longevidade, raças... Sabe-se o lugar crescente que esses problemas ocuparam desde o século XIX e que desafios políticos e econômicos eles vêm constituindo até hoje (FOUCAULT, 2002, p. 431).
\end{abstract}

Nesse contexto, a centralidade da vida ganha destaque e o saber médico se consolida como prática dominante sobre os corpos por ditar o que pode ser considerado "normal" e "patológico". Esse controle se estende, inclusive, às novas formas de desenvolvimento técnico-científico que o saber médico promoveu mediante pesquisas com células tronco e das tecnologias de reprodução assistida (PEREIRA, 2011). Numa linha de raciocínio semelhante, Cunha (2011) aponta que o desenvolvimento de células tronco embrionárias, para além de um consumo recluso à pesquisa científica, implica 
também na comercialização da vida mediante alterações de características fenotípicas que necessitam passar pelo crivo da bioética.

Até que ponto essas novas formas de agir sobre a vida, mediadas pela sofisticação do saber-poder médico não estariam criando crenças e representações compartilhadas sobre o corpo? Ou melhor, se seguirmos uma gramática foucaultiana, como tais realidades são produzidas por meio da construção de um discurso sobre o corpo? Para Perrusi (2001), tais elementos implicaram na legitimação de um padrão normativo sobre os corpos, com base no saber médico que implica numa normatividade social, preenchida pela individualidade e crença em dispositivos tecnológicos construídos com base num saberpoder científico. E o corpo, ao estar inserido nas relações sociais, teria, segundo Perrusi e Neves (2011), não apenas um âmbito físico e imediato, mas uma história imbricada no disciplinamento e normatização de comportamentos.

Com a pandemia de Covid-19, o imperativo do cuidado de si e dos outros toma um contorno mais impositivo e vigilante. Os dispositivos jurídicos e normativos são utilizados por países como China, Japão, Alemanha, Itália, Estados Unidos e Brasil, de modo a acionar - de forma legitimada — saberes e poderes para administrar a população e evitar os colapsos dos sistemas de saúde. Logo, termos como lockdown, "vigilância sanitária" e "vigilância epidemiológica" adentram no vocabulário cotidiano como reflexo de uma realidade mortificante (BEIGUELMAN, 2020). As cenas de corpos enterrados aos milhares em covas coletivas ocupam um imaginário compartilhado de que é necessário seguir critérios de biossegurança impostos pelo Estado. Das evidências de Han (2020) sobre a forma como a China tem feito uso de tecnologias de vigilância às restrições de circulação em âmbito mundial, passamos a viver um mundo distópico visto apenas no universo literário e cinematográfico.

\section{Balanço empírico: a Covid-19 no Brasil e o governo Bolsonaro}

Ao tomarmos como base o período que se inicia no dia $1^{\circ}$ fevereiro de 2020 até $1^{\circ}$ de fevereiro de 2021, constatamos que o cenário da pandemia no Brasil é um dos mais preocupantes do mundo. Segundo as estatísticas oficiais disponibilizadas pelo Ministério da Saúde, nesse espaço de tempo, o país teve um total de 225.099 óbitos acumulados, ficando atrás apenas dos Estados Unidos com um total de 439.955 segundo os dados do 
Centers for Disease Control and Prevention (CDC, 2021). Dentro do panorama global de óbitos por Covid-19, o Brasil concentrou um total de 10\% dessas mortes, acompanhado por México, Índia e Reino Unido. Apenas o Brasil e os Estados Unidos aglutinam cerca de $30 \%$ dos óbitos globais. ${ }^{2}$

Quando olhamos essa relação por milhão de habitantes, por levar em consideração as especificidades demográficas de cada formação social, constata-se que o panorama não se altera de forma significativa, uma vez que o Brasil, juntamente com Estados Unidos e México figuram entre os países com maiores índices entre os dez mais populosos do planeta, conforme podemos observar na tabela a seguir:

Tabela 1 - Mortes por Covid-19 por milhão de habitantes entre $1^{\circ}$ de fevereiro de

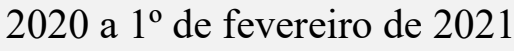

\begin{tabular}{lcc}
\hline País & Mortes por milhão de habitantes & População \\
\hline China & 3 & 1.439 .323 .776 \\
Nigéria & 8 & 209.112 .611 \\
Bangladesh & 49 & 165.653 .233 \\
Paquistão & 53 & 223.397 .006 \\
Îndia & 111 & 1.387 .975 .211 \\
Indonésia & 111 & 275.222 .063 \\
Rússia & 508 & 145.971 .424 \\
Brasil & 1.055 & 213.448 .530 \\
México & 1.226 & 129.728 .251 \\
Estados Unidos & 1.369 & 332.145 .637 \\
\hline
\end{tabular}

Fonte: Elaboração própria a partir de https://www.worldometers.info/coronavirus/.

Na presente reflexão, optamos por realizar os cálculos tendo como base o número de óbitos, uma vez que o diagnóstico da Covid-19 tem como questão a ausência de testes massivos para toda a população. Todavia, apenas em termos quantitativos, países como Estados Unidos, com um total acumulado de infectados na ordem de 26.921.020, e o Brasil com 9.230.865, apresentam-se como locais em que mais pessoas contraíram o SarsCov-2 no planeta. Essa mesma lógica se repete ao considerarmos o total de casos por milhão de habitantes, estando os Estados Unidos localizados na primeira posição com um

\footnotetext{
2 Calculamos esses índices com base no seguinte banco de dados: https://www.worldometers.info/ coronavirus/. Acesso em: 02 fev. 2021.
} 
índice de 81,05. O Brasil se encontra em sétimo lugar, com um total de 43,246 infectados por milhão de habitantes.

Ao redirecionarmos a escala de análise ao Brasil, percebemos que o país seguiu uma trajetória de difusão espacial que teve nas metrópoles o início da disseminação. Nesse sentido, cidades como São Paulo, Rio de Janeiro, Recife e Fortaleza concentraram inicialmente uma importação do Sars-Cov-2 por meio das viagens internacionais de avião. Esse movimento de contaminação pelo "ar" foi seguido de uma difusão terrestre pelas principais malhas viárias que cortam o território nacional. Em termos regionais, temos um panorama de maior concentração no Sudeste do país com a seguinte situação.

Gráfico 1 - Óbitos acumulados por região no Brasil entre $1^{\circ}$ de fevereiro de 2020 a $1^{\circ}$ de fevereiro de 2021

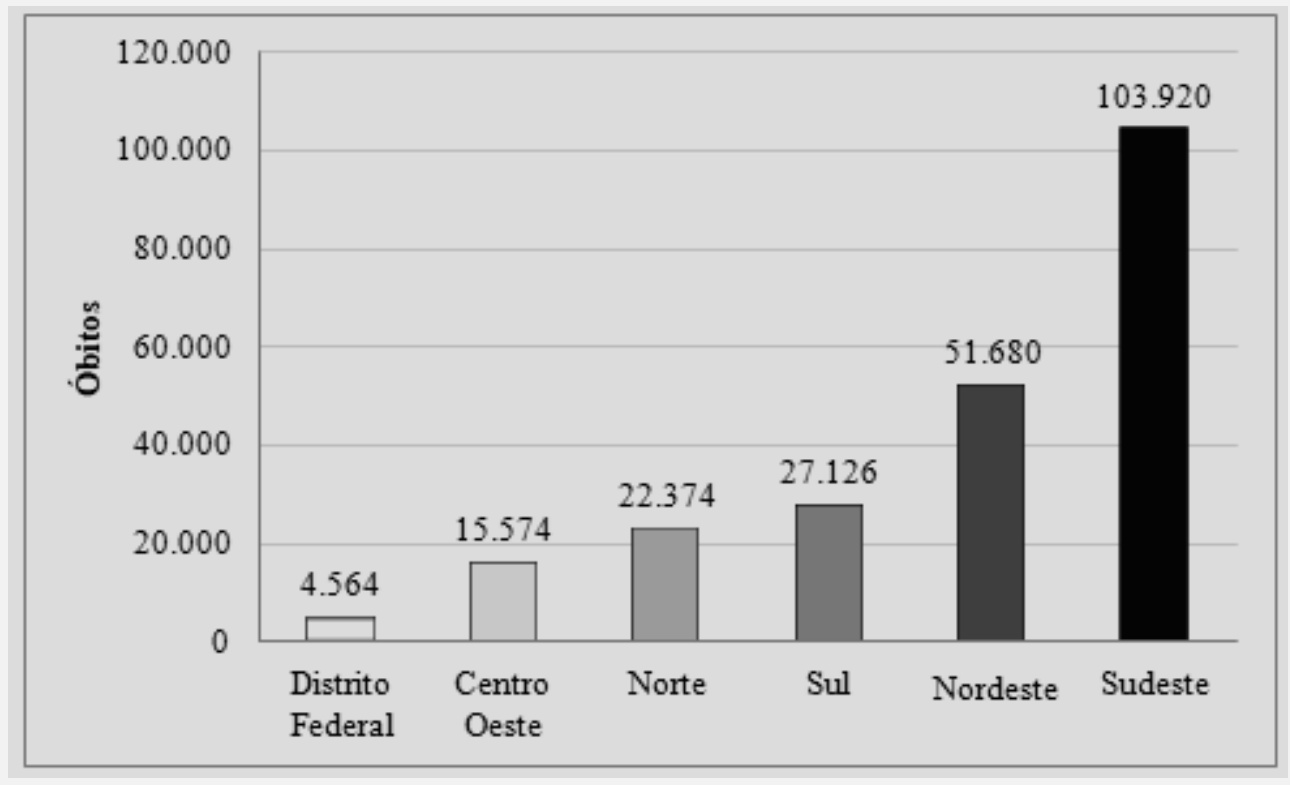

Fonte: Elaboração própria a partir de https://www.comitecientifico-ne.com.br/

Os estados que apresentam o maior número de óbitos dentro do espaço temporal analisado são: São Paulo (53.090); Minas Gerais (15.094); Rio Grande do Sul (10.715); Ceará (10.486) e Pernambuco (10.364). As cinco cidades com mais óbitos são: São Paulo (17.341); Rio de Janeiro (17.254); Manaus (5.693); Brasília (4.564) e Salvador (3.417). Nesse sentido, e tendo o Brasil por contexto, observa-se que a pandemia ainda apresenta altos índices de óbitos, chegando a uma média móvel de sete dias no valor de $1.048 \mathrm{em}$ 
$1^{\mathrm{o}}$ de fevereiro de 2021, segundo os dados disponibilizados pelo Comitê Científico do Consórcio Nordeste. ${ }^{3}$

Esse breve panorama dos óbitos e da distribuição espacial da Covid-19 no Brasil, serve como pano de fundo para o próximo tópico, que busca estabelecer uma conexão entre dispositivos jurídicos e a reflexão maior em torno da biopolítica. Cabe salientar que essa conexão não é uma transposição conceitual para a realidade brasileira, mas um esforço analítico de entender as especificidades de como um conjunto de normatização modelam a forma como o país tem enfrentado a Covid-19.

\section{Dispositivos normativos e a gestão da pandemia no Brasil}

Desde que a pandemia passou a figurar como tema central na política, economia e sociedade brasileira, um conjunto enorme de dispositivos jurídicos foram emitidos nas mais variadas instâncias do governo. Em termos empíricos, o Centro de Estudos e Pesquisas de Direito Sanitário (CEPEDISA), em parceria com a organização nãogovernamental Conectas Direitos Humanos, ${ }^{4}$ tem organizado um banco de dados a respeito desses dispositivos como podemos observar no gráfico a seguir:

Gráfico 2 - Dispositivos jurídicos vinculados à pandemia (1 de janeiro a 31 de dezembro de 2020)

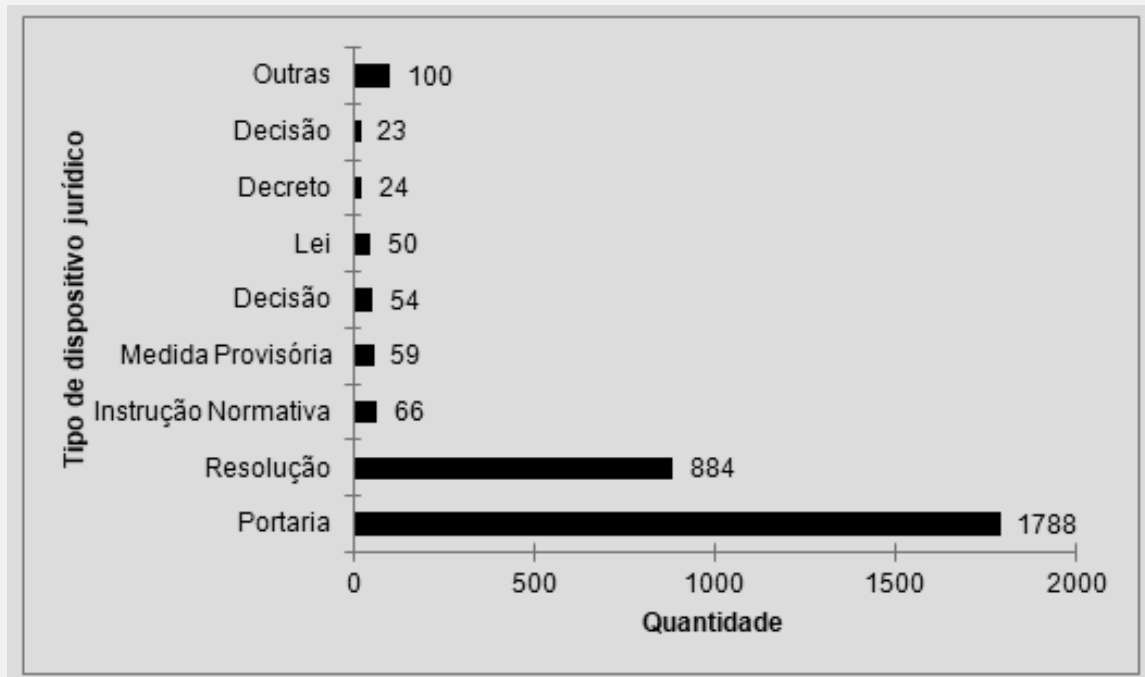

Fonte: Elaboração própria a partir de Cepedisa, 2021.

\footnotetext{
${ }^{3}$ Cf. http://www.consorcionordeste-ne.com.br/. Acesso em: 03 mar. 2021.

${ }^{4}$ Cf. https://www.conectas.org/ e http://cepedisa.org.br/publicacoes/. Acesso em: 05 fev. 2021.
} 
Ao todo foram elaboradas mais de 3.000 normas associadas à pandemia de Covid-19 em todo o país. O órgão que concentra o maior número de normatizações é o Ministério da Saúde com um total de 865 normativas, seguido pelo Ministério da Economia com 514; Agência Nacional de Vigilância Sanitária (ANVISA) com 382; Presidência da República com 166 e Ministério da Infraestrutura com 128. Conforme a análise desenvolvida por Ventura (2021), esse número de normas apresenta explicação no fato de a gestão da crise sanitária no Brasil ter sido realizada de forma descoordenada, com conflitos entre presidência da república, governadores e prefeitos, o que gerou dentro do marco do pacto federativo brasileiro, a produção desordenada e autônoma de normatizações. Para a nossa análise, a seleção dos dispositivos apresentados no quadro abaixo se justifica pelo fato de aglutinar as principais linhas de direção na gestão da crise sanitária que o governo Federal tem adotado em termos de biopolítica, residindo assim as principais medidas de enfrentamento; estabelecimento de serviços essenciais; direcionamento em relação à vacinação e controle de entrada e saída de pessoas do Brasil.

Quadro 1 - Normatizações selecionadas para observação e análise

\begin{tabular}{|c|c|c|}
\hline Dispositivo & Tema & Âmbito de origem \\
\hline $\begin{array}{l}\text { Lei } \mathrm{n}^{\circ} 13.979 \text {, de } 6 \\
\text { de fevereiro de } 2020\end{array}$ & $\begin{array}{l}\text { Dispõe sobre as medidas para enfrentamento } \\
\text { da emergência de saúde pública de } \\
\text { importância internacional decorrente do } \\
\text { coronavírus responsável pelo surto de } 2019\end{array}$ & Presidência da República \\
\hline $\begin{array}{l}\text { Decreto } \mathrm{n}^{\circ} 10.282, \\
\text { de } 20 \text { de março de } \\
2020\end{array}$ & $\begin{array}{l}\text { Regulamenta a Lei } \mathrm{n}^{\circ} 13.979 \text {, de } 6 \text { de } \\
\text { fevereiro de } 2020 \text {, para definir os serviços } \\
\text { públicos e as atividades essenciais. }\end{array}$ & Presidência da República \\
\hline $\begin{array}{l}\text { Plano Nacional de } \\
\text { Operacionalização } \\
\text { da Vacinação } \\
\text { contra a Covid-19 }\end{array}$ & $\begin{array}{l}\text { Estabelecimento de diretrizes para a } \\
\text { vacinação contra a covid-19. }\end{array}$ & Ministério da Saúde \\
\hline $\begin{array}{c}\text { Portaria } n^{\circ} 255 \text {, de } \\
22 \text { de maio de } 2020\end{array}$ & $\begin{array}{l}\text { Dispõe sobre a restrição excepcional e } \\
\text { temporária de entrada no país de } \\
\text { estrangeiros, de qualquer nacionalidade. }\end{array}$ & $\begin{array}{l}\text { Casa Civil da Presidência } \\
\text { da República e Ministérios } \\
\text { da Saúde; Infraestrutura; } \\
\text { Segurança Pública. }\end{array}$ \\
\hline
\end{tabular}

Fonte: Elaboração própria a partir das leis e decretos do governo federal. 
A Lei n 13.979/2020 (BRASIL, 2020a) pode ser considerada como a que desenha as diretrizes gerais no âmbito estatal das ações de combate à pandemia. Percebemos que o itinerário de "proteção à coletividade" é o enfoque base dessa lei. Como elemento constituinte de um poder sobre a vida, esse dispositivo emana o agenciamento que visa a separar pessoas infectadas e objetos contaminados como um meio de criar uma contenção espacial à proliferação viral. Sua outra faceta seria a instituição de quarentenas que tem por princípio a restrição de acesso aos objetos contaminados e indivíduos infectados. Além dessas medidas, a realização compulsória de exames clínicos; testes laboratoriais; coleta de amostras; vacinação; tratamento médico; exumação, necropsia, cremação e manejo de cadáver constituem um aparato normativo sobre a forma como o Estado deve manipular os corpos dos indivíduos. Sendo assim, as pessoas são compelidas a adotar práticas e regras sanitárias. O cerceamento nesse sentido é panóptico uma vez que o controle é exercido não apenas pelo Estado, mas também pela própria população que passa a introjetar e construir um sentimento de vigilância, repudiando aqueles que não usam máscaras, para citarmos apenas um exemplo.

Subjacente a essa tecnologia, o saber-poder sobre a vida também se manifesta no oitavo artigo da lei: "§ $1^{\circ}$ As medidas previstas neste artigo somente poderão ser determinadas com base em evidências científicas" (BRASIL, 2020a). O terreno de um saber-poder científico tem como função legitimar uma prática que se insere no campo biopolítico como norma e conduta que não podem ser contrariadas. Ao ter o poder de instituir o que é o "normal e patológico", a medicina, por exemplo, emana um controle biológico e sanitário sobre a vida, no qual atua de modo a concentrar autoridade sobre os corpos e condutas.

Nesse mote das restrições e controles, chama atenção o estabelecimento das atividades de caráter essencial. De acordo com Ventura (2021), houve por parte do Governo Federal uma clara intenção de proliferar o Sars-Cov-2 na população brasileira, com a implantação de estratégias de disseminação de informações inverídicas e vetos à lei para alargar a realização das atividades econômicas, e culpabilizar os demais setores pelo desempenho sanitário e econômico no país. A dicotomia entre vida e economia que o governo Bolsonaro aplica, além de uma intencionalidade prática no uso da ideia de "imunidade de rebanho", tem influenciado no controle e estabelecimento do que venha a 
ser essencial e o que não é. Essa determinação implica em colocar milhares de trabalhadores em plena atividade, num cenário em que o Brasil figura como um dos locais com mais óbitos pelo Sars-Cov-2:

[...] no Brasil de hoje, o caráter essencial de uma atividade durante a pandemia não está vinculado a uma avaliação técnica rigorosa, que busque conciliar o imperativo de conter a propagação da doença com a preservação do que é, de fato, indispensável à sobrevivência, à saúde ou à segurança da população, como definido pelo ordenamento jurídico, e sim depende do resultado da correlação de forças políticas na localidade em que a pessoa se encontrar, assim como às condições de acesso e ao posicionamento de cada instância do Poder Judiciário (VENTURA, 2021, p. 37).

Esse ponto da correlação de forças implica na existência de poderes diferenciados sobre o controle da vida. De modo simplificado, poderíamos considerar de um lado, frações da burguesia, especialmente as frações financeira e comercial sob o imperativo de uma governamentalidade neoliberal (DARDOT; LAVAL, 2020) procuram preservar o mercado em detrimento da proteção à vida. Do outro, temos o Supremo Tribunal Federal (STF), que toma uma posição aparentemente acima das classes, dando a impressão de se orientar por nuances técnicas, e temos ainda a oposição ao governo que realiza agitações nas mídias sociais no intuito de estabelecer uma biopolítica baseada em lockdowns, extensão do auxílio financeiro, isolamento social e vacinação em massa.

Desde o início da pandemia, a preocupação com a economia era o foco do Governo Federal. O histórico de ataques à saúde pública, conforme a pesquisa de Mendes e Carnut (2019) demonstra, é um retrato dessa realidade. A proposta de desvinculação orçamentária que Paulo Guedes - Ministro da economia —, buscou retirar do orçamento do Governo Federal, um total de R\$ 1,5 trilhão, expressa essa tendência que já vinha se agudizando no governo Temer com a Emenda Constitucional n ${ }^{\circ}$ 95/2016 (BRASIL, 2016). É preciso destacar que os dados econômicos de diversos países como Estados Unidos, China, e o próprio Brasil, demonstravam que a pandemia potencializou, mas não foi a causa do decrescimento da taxa de lucro, fenômeno abordado por Marx, ([1867] 2017), e mais recentemente com a crise econômica mundial de 2008, por intelectuais como Roberts, Carchedi (2018) e Roberts (2021).

Sem embargo, essa vinculação entre controle e poder sobre a vida é funcional ao modo de produção capitalista. Essa correlação é o que Foucault (2002) vai observar ao indicar que o surgimento do capitalismo necessitou de um regime padronizador sobre a 
vida e corpos dos indivíduos para a extração de mais-valor. Não é à toa que Frederick Taylor (1990), considerado o pai da "administração científica", realizou estudos sobre tempos e movimentos por meio da observação exaustiva da forma como os trabalhadores e trabalhadoras desempenham as funções nas fábricas, seu objetivo era normatizar os comportamentos e mecânicas exigidas para uma melhor eficiência e eficácia na produção.

Portanto a correlação entre tais elementos é o que aqui consideramos como dois aspectos existentes da biopolítica brasileira frente à Covid-19. Temos a conformação, por parte do governo Bolsonaro, do exercício de um poder que confirma a lógica do capital em detrimento da vida, mas também teríamos condutas que tentam realizar ações, aparentemente em "favor da vida", conforme mencionamos anteriormente, como também pelas ações de solidariedade, a exemplo do Projeto Mandacaru ${ }^{5}$, uma organização composta por voluntários que colaboram no sentido de encontrar soluções baseadas na ciência para o enfrentamento da pandemia, vinculado ao Comitê Científico de Combate ao Coronavírus do Consórcio Nordeste $(\mathrm{C} 4 \mathrm{NE})^{6}$, que vem realizando a articulação de ações e acompanhamento da pandemia na região Nordeste do país, sob coordenação do professor Miguel Nicolelis e do ex-ministro de Ciência e Tecnologia, Sérgio Machado Rezende.

Também identificamos no Governo Federal as tentativas de incluir no Decreto $\mathrm{n}^{\mathbf{0}}$ 10.282, de 20 de março de 2020 (BRASIL, 2020b), atividades que do ponto de vista objetivo poderiam ser desconsideradas num período de pandemia, a exemplo das atividades religiosas de qualquer natureza, salões de beleza, barbearias e academias. Para o presidente Bolsonaro, tais atividades são essenciais porque "garantem a vida" e resguardam empregos (MAZUI et al, 2021), embora ele não tenha feito nada para mudar o quadro de contrarreformas e precarização do trabalho.

Nesse mesmo contexto, o processo de vacinação também não foge à interpretação do escopo da biopolítica. No Brasil, o Plano de Operacionalização da Vacinação contra a Covid-19, lançado pelo Ministério da Saúde, é claro em eleger os indivíduos que devem

\footnotetext{
${ }^{5}$ Cf. Projeto Mandacaru. Disponível em: https://sites.google.com/view/pmandacaru. Acesso em: 10 mar. 2021.

${ }^{6}$ Cf. Comitê Científico de Combate ao Coronavírus do Consórcio Nordeste (C4NE). Disponível em https://www.comitecientifico-ne.com.br/. Acesso em 20 mar. 2021.
} 
ser imunizados num primeiro momento. ${ }^{7}$ São corpos classificáveis a partir de critérios epidemiológicos, que levam em consideração parcela da população mais afetada a partir da identificação de riscos:

[...] foram elencadas as seguintes populações como grupos prioritários para vacinação: trabalhadores da área da saúde (incluindo profissionais da saúde, profissionais de apoio, cuidadores de idosos, entre outros), pessoas de 60 anos ou mais institucionalizadas, população idosa (60 anos ou mais), indígena aldeado em terras demarcadas, comunidades tradicionais ribeirinhas e quilombolas, população em situação de rua, morbidades (Diabetes mellitus; hipertensão arterial grave (difícil controle ou com lesão de órgão alvo); doença pulmonar obstrutiva crônica; doença renal; doenças cardiovasculares e cérebro-vasculares; indivíduos transplantados de órgão sólido; anemia falciforme; câncer; obesidade grau III), trabalhadores da educação, pessoas com deficiência permanente severa, membros das forças de segurança e salvamento, funcionários do sistema de privação de liberdade, trabalhadores do transporte coletivo, transportadores rodoviários de carga, população privada de liberdade (BRASIL, 2021a, p. 22).

Salienta-se que a primeira versão do plano de imunização não contemplava comunidades tradicionais, ribeirinhas, quilombolas, trabalhadores do transporte coletivo, pessoas em situação de rua, população privada de liberdade; apenas após repercussão de instituições nas mídias sociais e posicionamento de pesquisadores que esses grupos foram incluídos no plano. Diante dessas especificações, cabe um destaque curioso de como a biopolítica também pode agir por dois polos inversos: o primeiro é esse protelado pela institucionalização de um dispositivo governamental lançado pelo Ministério da Saúde, que sofre interferência direta da Presidência da República, e o outro, seria a reivindicação de setores populares em oposição ao governo por outra biopolítica do "fazer viver", que lance mão de artifícios também institucionais para proteger as pessoas da Covid-19.

Em termos demográficos, a pandemia também revigorou lembranças de práticas que nos remetem ao período medieval. O controle das patologias como a da peste bubônica, ocasionado pelo agente etiológico Yersinia pestis, por exemplo, tinha no controle socioespacial uma das medidas para combater o contágio. $\mathrm{O}$ controle, quanto às navegações, circulação de pessoas e imigração, foi alvo de atenção dos governantes

\footnotetext{
${ }^{7}$ No momento de escrita do presente artigo (08 de fevereiro de 2021), um total de cinco instituições submeteram suas vacinas para análise da Agência Nacional de Vigilância Sanitária (ANVISA): AstraZeneca; Butantã; Fiocruz; Pfizer; Janssen. Dessas, apenas a CoronaVac (Butantan) e AstraZeneca foram aprovadas para uso emergencial. Até essa data, o Brasil conseguiu imunizar um total de 1.486 .461 pessoas numa população de 211,8 milhões de habitantes. Cf. https://localizasus.saude.gov.br/ e https://viz.saude.gov.br/extensions/DEMAS_C19Vacina/DEMAS C19Vacina.html. Acesso em 08 fev. 2021.
} 
daquele período. A pandemia de Covid-19, apesar de ocorrer em pleno século XXI, demonstra que o biopoder e a capacidade de intervir sobre a locomoção das pessoas não ficaram restritas ao passado. Uma das primeiras medidas que a China adotou ao identificar o potencial de contágio do Sars-Cov-2 em Wuhan foi realizar um cordão sanitário no território, impedindo a entrada e saída de pessoas da localidade como forma de conter a proliferação do vírus.

Contudo, com o desenvolvimento do meio técnico-científico-informacional (SANTOS, 2016) e com os avanços dos transportes e das conexões internacionais, temos a potencialização e disseminação de patógenos por todo mundo. Um determinado vírus pode circular o mundo em poucos dias, se inserindo em territórios diferenciados, o que acaba se tornando também um desafio, tal qual evidenciado pelo Sars-cov-2. Pode-se considerar que a entrada desse vírus no território brasileiro se deu por meio das viagens internacionais e de passageiros que tiveram contato com os principais corredores mundiais de proliferação, a exemplo da Itália. Metrópoles como Fortaleza, Recife, Salvador, São Paulo e Rio de Janeiro, devido à concentração de viagens desse tipo, foram as principais portas de entrada do vírus. Após esse momento, o contágio se deu pela via terrestre e pelo processo de interiorização, alcançando cidades de porte médio a pequenas (GUIMARÃES et al, 2020). Esse panorama implicou a exigência de um controle de locomoção especificado pelo Estado brasileiro, mediante a Portaria $n^{\circ} 255$, de 22 de maio de 2020 que proibiu a entrada no país, durante um período de trinta dias, de estrangeiros de qualquer nacionalidade (BRASIL, 2020c).

Essas restrições apresentaram impacto sobre a circulação de passageiros, se em termos globais a pandemia ocasionou uma redução de 70\% nos voos, no Brasil essa queda foi de 90\% (FARIA; YUKARI, 2020). Todavia, tais dados mostram apenas o que ocorre na superficialidade do fenômeno, o Brasil é o maior país da América do Sul, sua larga área fronteiriça com outros países da América Latina trouxe o debate sobre $o$ impedimento dos fluxos imigratórios, principalmente de países como Venezuela. Conforme Ramos (2021) salienta, ao apontar que o Brasil, por meio da Portaria Conjunta Interministerial $n^{0} 158$, de 31 de março de 2020, restringiu durante um período de trinta dias a imigração de pessoas oriundas daquele país. Além dessa portaria, o pesquisador também informa que a edição da Portaria Conjunta $n^{\circ} 255$ unificou o fechamento das fronteiras revogando as Portarias Interministeriais $n^{\circ} 201, n^{\circ} 203$ e $n^{\circ} 204$. Ademais, a 
Portaria $n^{\circ} 648$, de 23 de dezembro de 2020 promoveu o banimento de voos oriundos do Reino Unido; Grã-Bretanha e Irlanda do Norte devido ao desenvolvimento de novos tipos de cepas virais nesses territórios. O Reino Unido também tem impedido a entrada de pessoas que passaram pelo Brasil devido à descoberta de novas variações do Sars-Cov-2 no Amazonas (PINTO, 2021; NAVECA et al, 2021).

Tendo em vista esse panorama, o imperativo de um "fazer viver" é acionado pelo Estado que detém o poder de instituir práticas normativas de controle dos meios de transporte e da circulação das pessoas. Esse fato também é representado quando observamos a institucionalização do lockdown em municípios de estados como Maranhão; Amapá e Pará (OLIVEIRA; MELLO, 2020). A vigilância se aprofunda ainda mais quando passamos a ter por meio dos celulares conectados à internet e ao Global Positioning System (GPS), uma abertura para que empresas como Google tabulem dados sobre locomoção das pessoas.

Esses dados são utilizados pelos governos para calcular o nível de isolamento social conforme podemos observar na figura a seguir:

Figura 1 - Índice de isolamento social no Brasil entre $1^{\circ}$ de fevereiro de 2020 a $1^{\circ}$ de fevereiro de 2021

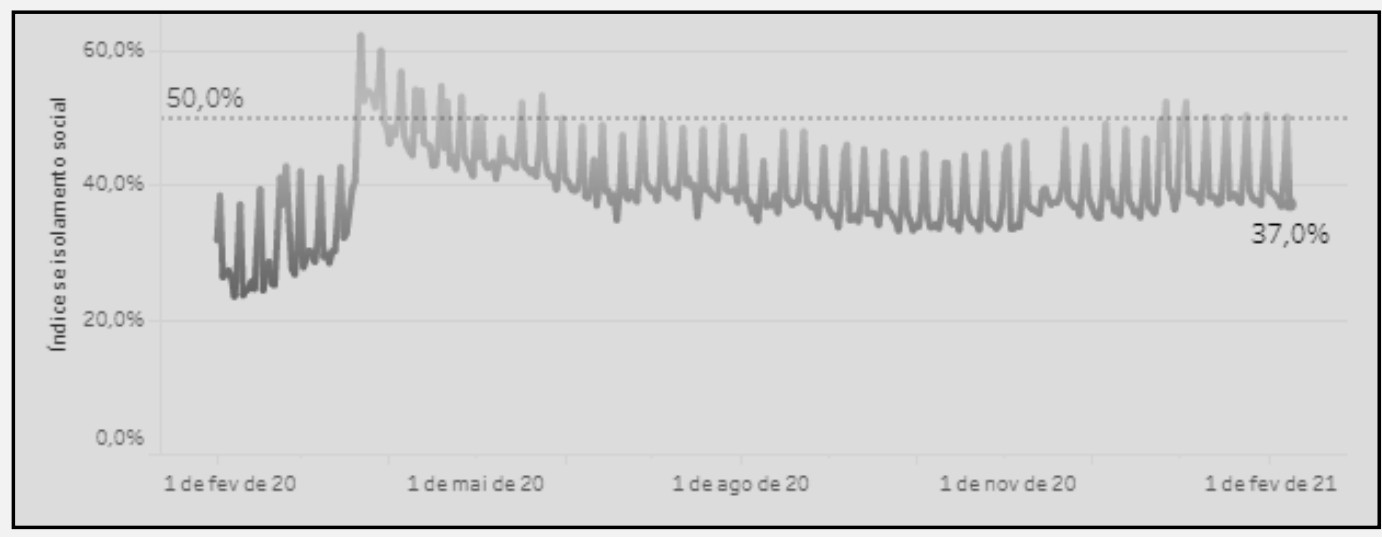

Fonte: https://mapabrasileirodacovid.inloco.com.br/pt/.

Essas estratégias e usos de dispositivos tecnológicos para realização do controle e monitoramento dos corpos já é uma prática comum em países como a China, conforme embasa Han (2020). Segundo esse pesquisador, o regime chinês realizou um alto grau de controle populacional mediante o uso de tecnologias, promovendo assim uma espécie de Estado com vigilância onipresente. 
No Brasil, conforme temos tentado compreender a situação pandêmica por meio dos dados empíricos, percebemos que, mesmo com a elaboração de medidas e decretos, há no cenário político, especialmente na cúpula organizacional do governo federal, a escolha tácita por fazer uso do biopoder para que a população tenha um maior contato com o Sars-Cov-2, e adquira uma imunidade de rebanho. Essa lógica é identificada na pesquisa de Ventura (2021), ainda que a autora não mencione as categorias de biopolítica e biopoder.

Por outro lado, a ideia de uma gestão sanitária para a contenção da proliferação do vírus por parte de alguns prefeitos e governadores passa a ideia aparente de se chocar com as proposições do presidente Bolsonaro. Todavia, essa "aparência" não tem conseguido superar a correlação de forças com a esfera federal, principalmente com a dicotomia criada entre economia e saúde. A culpabilização de prefeitos e governadores que não institucionalizam o uso do tratamento precoce com a Hidroxicloroquina, para citarmos um exemplo, o fechamento do comércio ou medidas restritivas de horários tem, em nossa interpretação, promovido que alguns entes cedam à pressão, especialmente num momento de crise econômica e desempregos. De modo igual, também não descartamos governadores e prefeitos que também surfam no negacionismo bolsonarista visando interesses eleitorais ou de vinculação ideológica ao presidente.

Cabe salientar que para a classe trabalhadora, principalmente da juventude precarizada, os trabalhadores de linha de frente da saúde, dos motoristas, empregadas domésticas, diaristas, enfim, de uma infinitude de categorias profissionais, o "direito" ao isolamento social não foi concedido. Além desse caráter de classe, destaca-se o recorte de classe e raça da pandemia. Segundo informações do Ministério da Saúde (BRASIL, 2021b), a população negra é a mais afetada pela Covid-19.

Ao nos debruçarmos sobre os dados referentes à escolarização e sua correlação com os óbitos na pandemia por meio da Pesquisa Nacional por Amostra de Domicílios - PNAD COVID-19 (IBGE, 2021), tendo como referência o mês de novembro de 2020, constatamos que as testagem realizadas para identificar as infecções pelo Sars-Cov-2 foram maiores na população branca, numa faixa etária de 30 a 59 anos de idade, que são mais escolarizadas e que possuem um nível de renda maior. De acordo com a pesquisa realizada por Ranzani et al (2021) que aborda a caracterização das primeiras 250.000 internações por Covid-19 no Brasil, no período de 16 de fevereiro a 15 de agosto de 2020 nas regiões: Norte, Nordeste e Centro-Oeste, os resultados indicam que cerca de $2 / 3$ das pessoas infectadas eram negros. Outras 
análises que corroboram essas constatações podem ser encontradas na pesquisa realizada pelo Núcleo de Operações e Inteligência em Saúde (NOIS), liderado pelo Departamento de Engenharia Industrial do Centro Técnico Científico da PUC-Rio (CTC/PUC-Rio), os dados consolidados de maio de 2020 com 30 mil casos encerrados indicam que praticamente $55 \%$ dos negros foram a óbito, em comparação com $38 \%$ dos autodeclarados brancos. A pesquisa também identificou que, pessoas sem escolaridade somaram uma taxa de $71 \%$ dos óbitos em relação aos 22\% daqueles com nível superior (BATISTA et al, 2020).

De acordo com o último boletim epidemiológico lançado no ano de 2020 pelo Ministério da Saúde (BRASIL, 2020d), que têm dados consolidado até o dia 28 de dezembro de 2020, negros somam um total de 38,1\% das hospitalizações por covid-19, brancos $37,7 \%$. Com relação aos óbitos, esse índice cresce tendo em vista que do total de 186.762 registradas no período, $42 \%$ foram de negros e $36 \%$ de brancos. Há também a evidência que uma menor renda e nível de escolaridade parecem indicar uma ligação direta entre a condição social, o lugar que ocupa o indivíduo na sociedade e a probabilidade de contrair Sars-Cov-2 e ir a óbito. Tais dados podem abrir margem para exploração de um conceito que, advindo de premissas foucaultianas, foi desenvolvido pelo filósofo camaronês Achile Mbembe. Na interpretação desse filósofo, o conceito de biopoder é relacionado à perspectiva de um estado de exceção, sendo uma expressão da capacidade de ditar quem pode viver e quem deve morrer. Contudo, Mbembe (2016) diz que em Foucault o direito soberano de matar e os dispositivos de biopoder estariam cravados na forma de funcionamento do Estado moderno, e que o nazismo seria um exemplo da concepção de um Estado exercendo o direito de matar. Todavia, diferentemente de Foucault, Mbembe argumenta que a atuação do biopoder já era existente no período colonial por meio da escravização de corpos negros. Ou seja, para ele a racialização discursiva já estava presente bem antes do que as análises de Foucault apontam.

Mbembe considera que a atenção dada a uma gestão da vida seria insuficiente para analisarmos as atuais transformações do curso histórico da humanidade, e que a gestão da morte seria de fato o que o Estado tem praticado em prol de realizar a manutenção de corpos eleitos para viver. A concepção expressa pelo autor pode ser entendida como necropolítica:

[...] as formas contemporâneas que subjugam a vida ao poder da morte (necropolítica) reconfiguram profundamente as relações entre resistência, sacrifício e terror. Demonstrei que a noção de biopoder é insuficiente para explicar as formas contemporâneas de subjugação da vida ao poder da morte (MBEMBE, 2016, p. 146, grifo nosso). 
Nesse sentido, a necropolítica e o necropoder seriam premissas que conseguiriam dar conta de como o Estado tem tratado as populações, priorizando a vida de uns em detrimento de outros. Do ponto de vista empírico e do que conseguimos observar ao trazer essas reflexões para o caso brasileiro, percebemos que a biopolítica, ao tratar de uma gestão da vida, promove intrinsecamente e de forma dialética uma gestão da morte ao eleger a forma como o Estados moderno deve regulamentar a vida dos indivíduos. Não obstante, a reflexão de Mbembe também é sumariamente profícua, conforme assevera Lima (2018), no sentido de apontar uma síntese entre a gestão da vida e da morte, principalmente com os recentes giros à direita na superestrutura política de países como o Brasil, com Bolsonaro, que tem realizado uma gestão da vida e da morte, na qual fica nítida a síntese entre bio/necropoder, ao desconsiderar medidas mínimas de segurança sanitária e potencializar o nível de óbitos por Covid-19 no Brasil, especialmente quando os dados empíricos nos apontam que grande parcela dos óbitos se localiza na população mais vulnerável quanto à classe e à raça.

\section{Considerações finais}

A pandemia de Covid-19 surge quando, por mais de três décadas, o imperativo neoliberal tem ditado a conduta das variadas formações econômico-sociais no mundo. Dos sistemas de saúde sucateados ao avanço do capital financeiro por meio do sistema da dívida pública, aliado a uma gestão sanitária baseada numa clara escolha pela Economia, o Brasil de Bolsonaro, mesmo tendo o SUS, considerado uma referência mundial em serviços de saúde, tem enfrentado altos índices de infecção e óbitos por Covid-19. Ao se tornar um dos epicentros de contaminação, o Brasil tem praticado uma biopolítica que tem falhado por não permitir uma gestão sobre a vida, de modo a salvar corpos do Sars-Cov-2, deixando morrer aqueles que, na interpretação de Bolsonaro, morreriam de qualquer forma, afinal, "todos morreremos um dia" (TARJA, 2020).

A nossa análise com base no levantamento bibliográfico e nos documentos consultados demonstra que o conceito de biopolítica pode ajudar nessa compreensão da gestão da crise sanitária que vivenciamos, desde que consideremos a perspectiva da formação social brasileira, de modo a não realizarmos uma simples transferência conceitual e aplicabilidade sem entender as especificidades do caso brasileiro. Os conflitos entre 
Presidência da República, governadores e prefeitos, além de uma série de ações emanadas pelo Governo Federal, demonstram que esse conceito não pode ser visto de forma unilateral, e que a leitura de Foucault também pode ser utilizada ao entendimento e análise sobre o Estado. Contudo, em nossa interpretação, ainda persiste a debilidade de não conseguir apreender, de conjunto ou no marco da totalidade, a correlação existente entre as classes sociais, o que pode abrir espaço para novas pesquisas.

Embora este artigo tenha objetivado refletir acerca da pandemia de Covid-19, por meio da leitura do conceito de biopolítica expresso pelo autor francês Michel Foucault, os resultados obtidos também fornecem subsídios para pensarmos a situação do SUS frente aos ataques do neoliberalismo e da forma como o governo Bolsonaro tem se tornado um grande promotor de mortes por todo o país. Se a pandemia de Covid-19 evidencia as fraturas de uma sociedade desigual, na qual ser negro e pobre é um indicativo de maior probabilidade de ir a óbito pelo Sars-Cov-2, a questão racial também é um elemento que pode ser investigado em futuras pesquisas por meio de indicadores sociais, mediante uma série temporal mais longa, para que assim possamos ter subsídios analíticos a novas interpretações, além de promover o amplo debate do porquê dados por raça, renda, escolaridade, em muitos casos, são de difícil acesso ou não ficam claros para a sociedade.

Nossa análise também evidenciou que a conformação da biopolítica no caso brasileiro se constitui de forma dialética, de modo a promover um dos mais trágicos momentos da saúde pública brasileira. A quantidade de óbitos referenciados por marcadores sociais exibem o nível de desigualdade existente na formação econômico-social brasileira. Esses aspectos podem ser aprofundados com análises que possam aglutinar as lacunas de investigação que apontamos, mas também promover dentro do âmbito das ciências sociais compreensões que aprofundem os pilares teóricos e empíricos que constituem esse campo do saber.

Dessa forma, se o conceito de biopolítica, conforme demonstramos no presente artigo, nos ajuda a pensar sobre a situação brasileira, isso não implica desconsiderar elaborações que também pensem em formas de superar esse quadro, especificamente aquelas atreladas ao entendimento das classes sociais no Brasil e nas suas relações com o Estado. E, talvez, certa limitação resida nesse ponto, pelo menos em nossa interpretação do marco teórico de Foucault, tendo em vista que se o Estado não é um bloco homogêneo e estático, tampouco as classes o são, há interesses ligados à própria materialidade da vida que também 
podem conformar outras possibilidades de biopolítica, uma que de fato valorize a vida e a saúde de forma ampla, e que não seja apenas um apêndice de um modelo de organização social baseado na acumulação de capital.

Frente a esses argumentos, avaliamos que dentro âmbito das ciências sociais, essas observações podem ser aprofundadas de modo a produzirmos novas sínteses, não apenas de interpretação, mas de intervenção. Ter em mente essa compreensão fornece subsídios para superação da chave analítica que considera o modelo de biopolítica empreendido pelo modo de produção capitalista como um fenômeno insuperável ou contínuo. Portanto, com base nas lacunas investigativas que sinalizamos e mediante os resultados obtidos no presente artigo, avaliamos a necessidade de novas elaborações e análises empíricas que podem ser realizadas no campo da saúde pública, contribuindo para o debate no campo das ciências sociais.

\section{Referências}

BATISTA, Amanda et al. Nota Técnica 11 - 27/05/2020. Análise socioeconômica da taxa de letalidade da COVID-19 no Brasil, Rio de Janeiro: NOIS, 2020. Disponível em: https://ponte.org/wp-content/uploads/2020/05/NT11-An\%C3\%A1lise-descritiva-dos-ca sos-de-COVID-19.pdf. Acesso em: 20 mar. 2021.

BAZZICALUPO, Laura. Biopolítica: um mapa conceitual. São Leopoldo: Unisinos. 2017.

BEIGUELMAN, Giselle. A pandemia das imagens: retóricas visuais e biopolíticas do mundo covídico. Revista Latinoamericana de psicopatologia Fundamental, São Paulo, v. 23, n. 3, p. 549-563, 2020. Disponível em: https://www.scielo.br/scielo.php?script=sci_arttext\&pid=S141547142020000300549. Acesso em: 16 jan. 2021.

BRASIL. Ministério da Saúde. Plano de Operacionalização da Vacinação contra a Covid-19. Brasília: Secretaria de Vigilância em Saúde, 2021a. Disponível em: https://www.conasems.org.br/wp-content/uploads/2021/04/1a-Edic\%CC\%A7a\%CC\%83o-Plano -Nacional-de-Vacinac\%CC\%A7a\%CC\%83o-contra-Covid_V1_16dez20.pdf. Acesso em: 08 fev. 2021. Acesso em: 08 fev. 2021.

BRASIL. Ministério da Saúde. Secretaria de Vigilância em Saúde. Boletim Epidemiológico no 44. 2021b. Disponível em: https://www.gov.br/saude/pt-br/media/pdf/2021/janeiro/07/boletim epidemiologico_covid_44.pdf. Acesso em: 20 mar. 2021.

BRASIL. Presidência da República. Lei no 13.979. Dispõe sobre as medidas para enfrentamento da emergência de saúde pública de importância internacional decorrente do coronavírus responsável pelo surto de 2019. 2020a Disponível em: https://www.in.gov.br/en/web/dou/-/lei-n13.979-de-6-de-fevereiro-de-2020-242078735. Acesso em: 20 mar. 2021.

BRASIL. Presidência da República. Decreto $\mathbf{n}^{\mathbf{0}}$ 10.212, de 20 de março de 2020. $2020 \mathrm{~b}$. Disponível em: http:/www.planalto.gov.br/ccivil_03/_ato2019-2022/2020/decreto/D10282.htm. Acesso em: 11 fev. 2021. 
BRASIL. Presidência da República. Portaria no 255, de 22 de maio de 2020. 2020c. Disponível em: https:/www.in.gov.br/en/web/dou/-/portaria-n-255-de-22-de-maio-de-2020-258114133. Acesso em: 09 fev. 2021.

BRASIL. Ministério da Saúde. Boletim epidemiológico $\mathbf{n}^{\mathbf{0}}$ 43. 2020d. Disponível em: https://coronavirus.saude.gov.br/boletins-epidemiologicos. Acesso em: 11 fev. 2021.

BRASIL, Presidência da República. Emenda Constitucional n. 95, de 15 de dezembro de 2016. 2016. Disponível em: http://www.planalto.gov.br/ccivil_03/constituicao/emendas/ emc/emc95.htm. Acesso em: 09 fev. 2021.

CAMUS, Albert. A peste. Rio de Janeiro: Record, [1947] 2012.

CDC. Covid data tracker. Site do Centers for Disease Control and Prevention. 2021. Disponível em: https://covid.cdc.gov/covid-data-tracker/\#datatracker-home. Acesso em: 20 mar. 2021.

CEPEDISA. Mapeamento e análise das normas jurídicas de resposta à Covid-19 no Brasil. Boletim Direitos na Pandemia. n. 10, São Paulo, 20 de janeiro de 2021. Disponível em: https://www.conectas.org/publicacoes/download/boletim-direitos-na-pandemia-no-10. Acesso em: 01 fev. 2021.

CUNHA, L. S. Células-tronco e a transcendência: a submissão do corpo vivo à biotécnica. CAOS - Revista Eletrônica de Ciências Sociais, v. 2, n. 18, p. 98-119, 2011. Disponível em: https://periodicos.ufpb.br/index.php/caos/article/view/47060. Acesso em: 21 jan. 2021.

DARDOT, Pierre; LAVAL, Christian. A prova política da pandemia. Blog da Boitempo. 2020. Disponível em: https://blogdaboitempo.com.br/2020/03/26/dardot-e-laval-a-prova-politica-dapandemia/. Acesso em: 20 jan. 2021.

DEFOE, Daniel. Um diário do ano da peste. Porto Alegre: Artes e Ofícios, [1722] 2014.

FARIA, Flávia; YUKARI, Diana. Coronavírus provoca redução de $90 \%$ dos voos no Brasil, mais que média global. Folha de São Paulo. Postado em 20 de abril de 2020. Disponível em: https://www1.folha.uol.com.br/mercado/2020/04/coronavirus-provoca-reducao-de-90-dos-voosno-brasil-mais-que-media-global.shtml. Acesso em: 09 fev. 2021.

FOUCAULT, Michel. O nascimento da clínica. 7. ed. Rio de Janeiro: Forense Universitária, [1963] 2011.

FOUCAULT, Michel. Nascimento da biopolítica. Curso dado no Collège de France (1978-1979). São Paulo: Martins Fontes, [1979] 2008.

FOUCAULT, Michael. Segurança, Território, População: Curso dado no Collège de France (1977-1978). São Paulo: Martins Fontes [1978] 2008.

FOUCAULT, Michael. Conferência 5. In: FOUCAULT, Michel. A verdade e as formas jurídicas. 3. ed. Rio de Janeiro: Nau Editora, 2002. p. 103 - 126.

FOUCAULT, Michel. Direito de morte e poder sobre a vida. In: FOUCAULT, Michel. História da sexualidade I: a vontade de saber. Rio de Janeiro: Edições Graal, 1988, p. 125 - 149.

GALEANO, Eduardo. As veias abertas da América Latina. Porto Alegre: L\&PM, [1971] 2010.

GUIMARÃES, Raul Borges et al. O raciocínio geográfico e as chaves de leitura da Covid-19 no território brasileiro. Estudos Avançados, São Paulo, v. 34, n.99, p.119-140, 2020. Disponível em: https://www.scielo.br/scielo.php?script=sci_arttext\&pid=S0103-40142020000200119\&lng=pt\&n rm=iso\&tlng=pt. Acesso em: 08 fev. 2021. 
HAN, Byung-Chul. Emergencia viral y el mundo de mañana. In: AGAMBEN, Giorgio.et al. A sopa de Wuhan: pensamiento contemporáneo en tiempos de pandemias. [Online], APSO, 2020, p. 97 - 112. Disponível em: https://drive.google.com/file/d/1bpWWb7X4CRi-VFyMIeQhtNE slFneKmqk/view. Acesso em: 08 fev.2021.

IBGE. Pesquisa Nacional de Amostragem por Domicílio. PNAD COVID-19. 2021. Disponível em: https://covid19.ibge.gov.br/pnad-covid/. Acesso em: 20 mar. 2021.

LIMA, F. Bio-necropolítica: diálogos entre Michel Foucault e Achille Mbembe. Arquivos Brasileiros de Psicologia, Rio de Janeiro, v. 70, n. spe, p. 20-33, 2018. Disponível em: http://pepsic.bvsalud.org/scielo.php?script=sci_arttext\&pid=S1809-52672018000400003\&lng-pt \&nrm=isso. Acesso em: 11 fev. 2021.

MARX, Karl. O capital: crítica da economia política. São Paulo: Boitempo, [1894] 2017. Livro III: o processo global de produção capitalista.

MAZUI, Guilherme et al. Coronavírus: Bolsonaro inclui salão, barbearia e academia como 'atividades essenciais'. Site Globo.com/G1. Postado em 11 de maio de 2020. Disponível em: https:/g1.globo.com/politica/noticia/2020/05/11/coronavirus-bolsonaro-inclui-salao-barbearia-eacademia-como-atividades-essenciais.ghtml. Acesso em: 20 mar. 2021.

MBEMBE, A. Necropolítica. Arte e Ensaios, Rio de Janeiro, v. 2, n. 32, p. 123-151, 2016. Disponível em: https://revistas.ufrj.br/index.php/ae/article/view/8993/7169. Acesso em: 11 fev.2021.

MENDES, Áquilas; CARNUT, Leonardo. Desvinculação orçamentária de Guedes mata a saúde pública. Revista Domingueira da Saúde, Campinas, v. 10, p. 1-4, 2019. Disponível em: http:/idisa.org.br/domingueira/domingueira-n-10-marco-2019?lang-pt. Acesso em: 27 mar.2021.

NAVECA, Felipe et al. Nota técnica 2021/01. Relação filogenética de sequências SARS-CoV-2 do Amazonas com variantes emergentes brasileiras que abrigam mutações E484K e N501Y na proteína Spike. Rio de Janeiro: Fiocruz/Ministério da Saúde. 2021. Disponível em: https://portal.fiocruz.br/noticia/fiocruz-publica-nota-tecnica-sobre-nova-variante-do-sars-cov-2no-amazonas. Acesso em: 09 fev. 2021.

OLIVEIRA, Lorena. O conceito de governamentalidade em Michel Foucault. Ítaca, Rio de Janeiro, n. 34, p. 48-72, 2019. Disponível em: https://revistas.ufrj.br/index.php/ Itaca/article/view/26395/18009. Acesso em: 20 Mar. 2021.

OLIVEIRA, Marcelo; MELLO, Igor. Saiba em que estados e cidades já foi decretado o lockdown no Brasil. Site do Uol. Postado em 15 de maio de 2020. Disponível em: https://noticias.uol.com.br/saude/ultimas-noticias/redacao/2020/05/09/saiba-onde-ja-foidecretado-o-lockdown-no-brasil.htm. Acesso em 20 Mar. 2021.

PELBART, Peter Pál. Vida capital: ensaios de biopolítica. São Paulo: Iluminuras, 2003.

PEREIRA, M. P. M. Corpo, saúde e novas tecnologias reprodutivas. CAOS - Revista Eletrônica de Ciências Sociais, João Pessoa, v. 2, n. 18, p. 51-62, 2011. Disponível em: https://periodicos.ufpb.br/index.php/caos/article/view/47054. Acesso em: 21 jan. 2020.

PERRUSI, A. Utopia da saúde perfeita: a nova ideologia do corpo na modernidade. CAOS Revista Eletrônica de Ciências Sociais, v. 1, n. 3, 2001. Disponível em: https://periodicos.ufpb.br/index.php/caos/article/view/47126. Acesso em: 21 jan. 2021.

PERRUSI, A.; NEVES, E. M. Apresentação: dossiê corpo e saúde. CAOS - Revista Eletrônica de Ciências Sociais, v. 2, n. 18, p. 01-03, 2011. Disponível em: https://periodicos.ufpb.br/index.php/caos/article/view/47047. Acesso em: 21 jan. 2021. 
PINTO, Ana Estela de Sousa. Reino Unido proíbe entrada de viajantes do Brasil devido a variante do coronavírus. Folha de São Paulo. 14 de janeiro de 2021. Disponível em: https://www1.folha.uol.com.br/mundo/2021/01/reino-unido-proibe-entrada-de-viajantes -do-brasil-por-causa-de-variante-do-coronavirus.shtml. Acesso em: 09 fev. 2021.

RAMOS, André de Carvalho. Migração e pandemia: o fechamento das fronteiras. Boletim Direitos na Pandemia. São Paulo, n. 10, p. 48-53, 2021. Disponível em: https://www.conectas.org/publicacoes/download/boletim-direitos-na-pandemia-no-10. Acesso em: 01 fev. 2021.

RANZANI, Otavio et al. Characterisation of the first 250000 hospital admissions for covid-19 in Brazil: a retrospective analysis of nationwide data. The Lancet Respiratory Medicine, Londres, v. 9, p. 407-418, 2021. Disponível em: https://www.thelancet.com/journals/lanres/article/PIIS22132600(20)30560-9/fulltext\#\%20. Acesso em: 11 fev. 2021.

ROBERTS, Michael. Covid and fictitious capital. Michael Roberts blog: blogging from a marxist economist. 2021. [Online]. Disponível em: https://thenextrecession.wordpress. com/2021/01/25/covid-and-fictitious-capital/. Acesso em: 05 fev. 2021.

ROBERTS, Michael; CARCHEDI, Guglielmo. The long depression: marxism and the global crisis of capitalism. Chicago: Haymarket Books, 2018.

SANTOS, Milton, 1926-2001 A natureza do espaço: técnica e tempo, razão e emoção. 4. ed. São Paulo: Editora da Universidade de São Paulo, 2006.

TARJA, Alex. Todos nós vamos morrer um dia: veja falas de Bolsonaro sobre o coronavírus. Site Uol. Postado em 01 de maio de 2020. Disponível em: https:/noticias.uol.com.br/saude/ultimasnoticias/redacao/2020/05/01/todos-nos-vamos-morrer-um-dia-as-frases-de-bolsonaro-durante-apandemia.htm. Acesso em: 01 mar. 2021.

TAYLOR, Frederick Winslow. Princípios de administração científica. São Paulo: Atlas, [1911] 1990.

VENTURA, Deisy. Atividades consideradas essenciais no brasil. durante a pandemia: as discrepâncias entre normas federais e estaduais. Boletim Direitos na Pandemia. São Paulo, n. 10, p. 32-37, 2021. Disponível em: https://www.conectas.org/publicacoes/download/ boletim-direitos-na-pandemia-no-10. Acesso em: 01 fev. 2021.

WHO. World Health Organization. Coronavirus disease (COVID-19). Postado em 12 de outubro de 2020. Disponível em: https://www.who.int/emergencies/diseases/novel-coronavirus2019/question-and-answers-hub/q-a-detail/coronavirus-disease-covid-19. Acesso em: 20 mar. 2021.

Recebido em: 03/03/2021.

Aceito em: 08/04/2021. 